УДК 338.45

ББК 65.30

АКТУАЛЬНЫЕ ТЕНДЕНЦИИ РАЗВИТИЯ УСЛУГ ПРОМЫШЛЕННОГО ХАРАКТЕРА В РЕСПУБЛИКЕ БЕЛАРУСЬ В КОНТЕКСТЕ ТЕРЦИАЛИЗАЦИИ ПРОМЫШЛЕННОСТИ*

\author{
Ю.В. МЕЛЕШКО \\ meleshkojv@gmail.com \\ кандидат экономических наук, доцент кафедры «Экономика и право» \\ Белорусский национальный технический университет \\ г. Минск, Республика Беларусь
}

В статье рассматриваются актуальные тенденции развития услуг промылиленного характера в Республике Беларусь как одного из основных факторов терциализации промышленного производства. На примере организационной структуры предприятия Siemens демонтируется возрастание значения услуг промышленного характера в современном промышленном производстве, обусловленном переориентащией предприятий от простого производства продукиии к предложению комплексных решений. Выделены и охарактеризованы следующие направления развития услуг промышленного характера в Республике Беларусь: НИОКР; услуги, сопровождающие промышленную продукиию, в том числе инжиниринговые услуги; информационно-коммуникационные услуги.

Ключевые слова: услуги промышленного характера, терциализация промышленности, НИОКР, инжиниринг, информационно-коммуникационные услуги, услуги, сопровождающие промышленную продукцию.

\title{
CURRENT TENDENCIES OF DEVELOPMENT OF INDUSTRIAL SERVICES IN THE REPUBLIC OF BELARUS IN THE CONTEXT OF INDUSTRY'S TERTIALIZATION
}

\section{Yu.V. MELESHKO}

$\mathrm{PhD}$ in Economics, Associate Professor of the Department of Economics and Law Belarusian National Technical University

Minsk, Republic of Belarus

The article discusses the current trends in the development of industrial services in the Republic of Belarus as one of the main factors for the tertialization of industry. Using the example of the organizational structure of the Siemens AG, the growing importance of industrial services in modern industrial production is being dismantled, due to the reorientation of enterprises from simple production to offering complex solutions. The following areas for the development of industrial services in the Republic of Belarus were identified and characterized: $R \& D$, product-accompanying services, including engineering, information and communication services.

Keywords: industrial services, tertialization of industry, $\mathrm{R} \& \mathrm{D}$, engineering, information and communication services, product-accompanying services.

\footnotetext{
* Статья подготовлена в рамках договора с БРФФИ № Г17М-017 от 18.04.2017 г.
} 


\section{ВВЕДЕНИЕ}

Изменения в структуре современной экономики произошли не только в части перераспределения долей в ВВП между первичными, вторичным и третичным секторами экономики в сторону увеличения доли сферы услуг, но затронули и качественные аспекты всех трех секторов. При этом определяющим фактором стало изменение характера современного производства, становящегося все более индивидуальным и высокотехнологичным. Возрастающая степень индивидуальности производства способствует вовлечению в производственный процесс все большего количества и все более разнообразных услуг промышленного характера. Необходимость индивидуализации продукции изменила приоритеты в отношении отдельных звеньев цепочки создания стоимости: на первый план выходят проектирование и разработка и послепродажное обслуживание, а не само производство, что стало новым толчком для развития таких услуг промышленного характера как НИОКР, инжиниринг, дизайн, а также ряд маркетинговых услуг, нацеленных на долгосрочную работу с клиентами.

Новые технические возможности диджитализации информации и ее использования способствуют не только сохранению тенденции терциализации экономики, и промышленности в частности, но и углублению этой тенденции. А. Айкельпаш справедливо утверждает: «Терциализация обрабатывающей промышленности возрастает. < ..> Исследования занятости на базе социальных выплат показали, что сдвиг от деятельности по изготовлению продукции к услугам промышленного характера является постоянно продолжающимся процессом. В особенности такие продуктоориентированные услуги как НИОКР, технические услуги, услуги по управлению и организации развивать более выгодно, чем непосредственно производство» [1, Р. 24]. Иными словами, сегодня услуги промышленного характера занимают все большее место в промышленном производстве и все большая часть добавленной стоимости формируется именно в секторе услуг промышленного характера, а не в секторе производства.

\section{РЕЗУЛЬТАТЫ И ИХ ОБСУЖДЕНИЕ}

Тенденции терциализации промышленного производства проявляются, в том числе, в изменении организационной структуры промышленных предприятий. Крупнейшие компании, являющиеся лидерами промышленного производства на международном уровне, при структурировании своей деятельности не противопоставляют производственные процессы и сопутствующие услуги. Например, на предприятии Siemens действуют следующие департаменты, «образующие промышленный базис» [2, p. 2]:

департамент электроэнергетики и газа, предлагающий широкий спектр продуктов и решений для производства электроэнергии из ископаемых видов топлива, а также для производства и транспортировки нефти и газа;

департамент ветроэнергетики и возобновляемых источников энергии, разрабатывающий, производящий и устанавливающий ветровые турбины для наземного и морского применения;

департамент управления электроэнергией, предоставляющий широкий спектр продуктов, систем, решений, программного обеспечения и услуг для передачи и распределения электроэнергии и для развития умной сетевой инфраструктуры;

департамент строительных технологий, предлагающий продукты, решения, услуги и программное обеспечение для пожарной безопасности, безопасности, автоматизации зданий, отопления, вентиляции, кондиционирования воздуха и управления энергией; 
департамент транспорта, создающий продукцию в области пассажирских и грузовых перевозок, включая железнодорожные транспортные средства, системы автоматизации железных дорог, системы электрификации железнодорожного транспорта, технологию дорожного движения, ИТ-решения и сопутствующие услуги;

департамент цифрового производства, предоставляющий комплексный портфель продуктов и системных решений, используемых в обрабатывающей промышленности, дополненный услугами по компьютерному управлению данными и услугами отслеживания жизненного цикла продукции (технологии «умных заводов» - примечание Ю.М.);

департамент непрерывного производства и приводов, создающий комплексный портфель продуктов, программного обеспечения, решений и услуг для перемещения, измерения, управления и оптимизации всех видов расходов массы (также относится к технологиям «умных заводов»- примечание Ю.М.);

департамент медицинских услуг, специализирующийся на медицинских технологиях и программных решениях, а также клинических консультационных услуг, поддерживаемых полным набором учебных и сервисных предложений [2, p. 2-3].

Из приведенного выше описания структурных подразделений Siemens и их функций видно, что вся производимая продукция (газовые турбины, паровые турбины, генераторы, компрессорные поезда, приборы и системы управления, ветровые турбины наземного и морского применения, транспортные средства и т. д.) сопровождается соответствующими услугами промышленного характера. Каждый из названных департаментов предлагает не только промышленную продукцию, но и сопутствующие «решения и услуги», тем самым создавая комплексные решения. За счет интеграции таких услуг ключевым фактором конкурентоспособности предприятия становится не реализация высокотехнологичной и качественной продукции, а предложение комплексных решений в области производства электроэнергии, транспортных коммуникаций, строительства, «умных заводов».

Специалисты также отмечают, что тенденция терциализации характерна для всех видов промышленной деятельности, но характеризуется различной интенсивностью. Анализ продуктовой структуры затрат отечественных товаров производственной сферы на услуги, показал, что среди видов деятельности, относящихся к сфере производства, основными потребителями услуг (торговля; ремонт автомобилей, бытовых изделий и предметов личного пользования; транспорт; связь; финансовая деятельность; операции с недвижимым имуществом, аренда и предоставление услуг потребителям; образование) в 2015 г. были: производство машин и оборудования (доля услуг в затратах составила в 2015 г. 21,39 \%), добыча топливно-энергетических полезных ископаемых (20,58 \%), производство и распределение электроэнергии, газа и воды $(20,18 \%)$, производство транспортных средств и оборудования $(18,9 \%)$, строительство $(18,79 \%)$, химическое производство (16,91 \%), целлюлозно-бумажное производство, издательская деятельность $(15,98 \%)$, производство электрооборудования, электронного и оптического оборудования $(14,41 \%)$, текстильное и швейное производство (доля услуг в затратах которого составляет 14,78 \%), производство кокса, нефтепродуктов и ядерных материалов $(14,75 \%)$. В этом же году наименьшую долю в структуре затрат услуги составляли в производстве пищевых продуктов, включая напитки, и табака (4,05\%), сельском хозяйстве, охоте и предоставление услуг в этих областях (4,83 \%), рыболовстве, рыбоводстве и предоставление услуг в этих областях $(5,76 \%)$ [3, с. 68-70].

Таким образом, в Республике Беларусь среди отраслей обрабатывающей промышленности лидерами в потреблении услуг являются химическое производство, производство электрооборудования, электронного и оптического оборудования, производство 
транспортных средств и оборудования и производство машин и оборудования. Примечательным является то, что в соответствии с Общегосударственным классификатором Республики Беларусь «Виды экономической деятельности» эти же виды деятельности относятся к наукоемким или высокотехнологичным и среднетехнологичным производствам высокого уровня. Такая зависимость между потреблением услуг промышленного характера и технологическим уровнем производства позволяет сделать вывод о важном значении услуг промышленного характера в развитии наукоемких и высокотехнологичных производствах.

В Германии наиболее явно тенденция терциализации промышленности выражена в экспортоориентированных отраслях (автомобильная промышленность, машиностроение, электротехническая отрасль, а также химическая и фармацевтическая индустрия) [4]. Кроме того, что эти отрасли относятся к высокотехнологичным и среднетехнологичным производствам высокого уровня, они являются наиболее конкурентоспособными на национальном и международном рынках, являясь участниками (ключевыми звеньями) транснациональных корпораций. «Реальностью современного мирового экономического порядка стала глобализация производства, сопровождаемая становлением и бурным развитием транснациональных корпораций, - пишет С. Ю. Солодовников. - Последние выходят из-под контроля национальных государств. Одновременно с развитием ТНК возрастает борьба между последними как за передел уже существующих рынков, так и за захват новых (причем количество последних сегодня пространственно ограничено)» [5, с. 19].

Как было отмечено, «конкурентоспособность продукции в эпоху четвертой промышленной революции обеспечивается за счет использования инноваций, направленных, в первую очередь, на качественное изменение производимой продукции, а не на снижение затрат» [6]. По мере возрастания клиентоориентированности промышленной продукции основные усилия предприятий распределяются в двух направлениях: создание качественно новой продукции, отличной от продукции конкурентов, и развитие клиентских сервисов (как допродажного, так и послепродажного обслуживания). В связи с этим «особое значение приобретают услуги по разработке и внедрению продукции в производство (НИОКР, дизайн, инжиниринг и т. д.) и услуги, сопровождающие промышленную продукцию (маркетинговые услуги, проектирование, консалтинг, профессиональное обучение и т. д.)» [6].

Услуги по разработке и внедрению продукции в производство направлены на создание новой продукции и (или) новых технологических решений ее производства. По мере ужесточения международной конкуренции значение таких услуг возрастает, поскольку именно использование результатов НИОКР позволяют предприятиям добиться уникальных конкурентных преимуществ и сформировать базу для дальнейшего роста. В Германии с 2008 г. по 2013 г., после существенного спада, хотя и меньшего, чем в самом промышленном производстве, деятельность в сфере НИОКР ежегодно увеличивалась в среднем на 3,2 \% [7, Р. 695]. В 2013 г. доля НИОКР в создании добавленной стоимости в среднем по промышленности Германии составила 12,7 \% (в 2011 г. - 11,3 \%), при этом для наиболее наукоемких отраслей промышленности этот показатель равнялся 22,6 \%, а лидером стало автомобилестроение (30,9 \%) [7, p. 702-703]. 45\% оказываемых НИОКР в Германии потребляются обрабатывающей промышленностью $[8, \mathrm{p}$. 21]. Опыт немецкого промышленного комплекса показал, что предприятия, осуществляющие научные исследования и разработки, оказались более устойчивыми к кризису 2008-2009 гг., в первую очередь, за счет сохранившегося экспорта. Таким образом, по мере дальнейшей интернационализации производства и изменение структуры национальной промышленности в сторону увеличения отраслей пятого и шестого технологических укладов значение услуг по разработке и внедрению продукции в производство 
будет возрастать. Вместе с тем объективными ограничениями для развития этих услуг выступают необходимость существенных затрат, в первую очередь, финансовых и временных, и наличие кадрового обеспечения. Сложность и дороговизна научных исследований и разработок становится причиной того, что не все промышленные предприятия могут себе это позволить, в особенности малые и средние.

Проблематика проведения НИОКР предприятиями белорусского промышленного комплекса широко освящается в научной литературе. Специалистами отмечается: «Сегодня важно, чтобы в центре внимания всей прикладной белорусской науки находились нужды реального сектора экономики - ядра экономической системы общества, - что требует разработки системы критериев для выяснения социально-экономической эффективности импорта той или иной технологической инновации или же разработки ее отечественными специалистами. Исходя из постсоветских белорусских реалий, в настоящее время невозможно прекратить государственное финансирование прикладных исследований, поскольку Национальная академия наук должна взять на себя часть прикладных исследований, которыми раньше занимались отраслевые институты, рухнувшие за годы перестройки» [9, с. 6]. В целом же, для Республики Беларусь, не обладающей значительными собственными запасами сырьевых ресурсов, «в условиях осуществления социально-экономических реформ, ориентированных на построение и развитие социальноориентированной рыночной экономики с включением в систему мирохозяйственных связей», проблематика «повышения роли науки в обществе, увеличения и обновления научнотехнического потенциала будет в ближайшие годы особенно актуальной» [10, с. 443]. Корни проблем «расширенного воспроизводства социально-научного сообщества» описываются С.Ю. Солодовниковым, который отмечает помимо лежащих на поверхности явлений («... старение научных и научно-педагогических кадров высшей квалификации, снижение престижности научного труда, проблемы подготовки кадров высшей квалификации и т. д.»), также более глубокие обстоятельства, «которые не всегда очевидны, но ещё более опасны - это, прежде всего, снижение социального капитала науки; устойчивая тенденция к "автаркии" научного воспроизводства и угроза потери тех возможностей, которые были в рамках СССР и служили подпиткой как для развития старых, так и возникновения новых научных и инженерных школ; преобладание эмпирически очевидных подходов при принятии управленческих решений на государственном уровне и т. д.» $[11$, с. 9.]. Л. П. Васюченок, в качестве решения проблемы взаимодействия фундаментальной науки, прикладной науки и бизнеса, предлагает внедрение интерактивной модели трансфера технологий, которая «позволяет вовлечь в инновационный процесс гораздо более широкий круг субъектов, создает внутренние стимулы для инноваций, предлагает гибкие организационные формы инновационной деятельности и способы привлечения ресурсов, поощряет горизонтальные и междисциплинарные связи участников передачи технологий, что ведет к новому качеству экономического роста и повышению конкурентоспособности белорусской экономики» [12, с. 93].

Одной из ключевых тенденций, характеризующих изменение современного промышленного производства, является увеличение сервисной составляющей в промышленной продукции. Ю. А. Андриянова справедливо отмечает: «Потребители чаще стали обращать внимание не столько на продукцию, ее характеристики и свойства, сколько на услуги, связанные с расширенными возможностями ее потребления, содержания и эксплуатации. Причем многие услуги интересуют потребителя не в отдельности, а в комплексе. Именно о предоставлении комплекса услуг (в него входят основной процесс услуги и ряд дополнительных возможностей) задумывается потребитель, отдавая широкому спектру услуг свое предпочтение» [13, с. 9]. 
В соответствии с современной международной классификацией сервисные услуги включаются в группу услуг, сопровождающих промышленную продукцию (нем. produktbegleitende Dienstleistungen), под которыми понимаются услуги, которые «продаются совместно с промышленной продукцией вне зависимости от того, создаются ли такие услуги самостоятельно или закупаются извне» [14, p. 1408]. Ключевой отличительной характеристикой услуг, сопровождающих промышленную продукцию, является то, что движение товаров неразрывно связано с потреблением услуг.

Высокие темпы роста этих услуг объясняются в зарубежной экономической литературе следующим образом: «Все сложнее добиться успеха на мировом рынке с отдельными продуктами, которые предлагаются изолировано. Поскольку здесь международная конкуренция постоянно возрастает, молодые индустриальные страны могут противопоставить ценовые преимущества. Поэтому все большее значение приобретают "системные решения", которые позволяют предлагать высокотехнологичную продукцию вместе с дополнительными услугами» [15]. По результатам опроса Института экономических исследований Германии доля предприятий, предлагающих такие услуги, возросла с $16 \%$ в 2011 г. до 25 \% в 2015 г. [1, p. 28]. Согласно исследованию Bain \& Company на сервисное обслуживание приходится около четверти доходов и около половины прибыли многих европейских производителей промышленной продукции [16].

Услуги, сопровождающие промышленную продукцию, весьма разнообразны по содержанию и форме их оказания. Ф. Стилле отмечает, что такие услуги могут оказываться «совместно с продуктом, который еще только будет доставлен (например, проектирование или консалтинг), с уже купленным продуктом (например, сервисное обслуживание или обучение) или с уже использованным продуктом (демонтаж или утилизация)» [17]. Б. Бинцайслер и М. Кундис указывают на различную степень интегрированности с материальным носителем, например, эти услуги могут являться аддитивными, как сервисное обслуживание автомобиля или же интегрированной составной частью индивидуального системного решения [18]. Однако, вне зависимости от формы, ключевой характеристикой услуг, сопровождающих промышленную продукцию, является их клиентоориентированность. При помощи этих услуг производителям удается сделать свою продукцию более разнообразной, отличающейся от продукции конкурентов, способной удовлетворить индивидуальные требования покупателя. Особенно эффективно используются услуги, сопровождающие промышленную продукцию, на рынках с высокой ценовой конкуренцией и низким уровнем дифференцированности продукции. Также эти услуги помогают устанавливать более тесную взаимосвязь с клиентами и повышают возможность кросс-продаж. Н. И. Ивашкова справедливо отмечает: «Сегодня многие промышленные компании - производители технологического оборудования включают в свою стратегию развитие сервисных услуг. Конечно, услуги по пуско-наладке и техническому обслуживанию сопровождают многие промышленные товары, но если раньше они рассматривались как обязательство перед покупателями - низкомаржинальный либо вообще бесприбыльный бизнес, то сейчас они переходят в разряд выгодного растущего сегмента бизнеса. А в дальнейшем бизнес-модель промышленного предприятия должна совмещать в себе как производство оборудования, так и промышленные услуги» [19, с. 74].

Среди услуг, сопровождающих промышленную продукцию, наиболее распространенными являются инжиниринговые услуги. В 2014 г. доля инжиниринговых услуг в промышленном сегменте экономики США достигла 17 \%, Европы 13 \%, отдельно Германии 20 \%. В России этот показатель находился на уровне $2 \%$ [20]. 40 \% оказываемых инжиниринговых услуг в Германии потребляются обрабатывающей промышленностью $[8$, p. 21]. Рынок инжиниринговых услуг является одним из первых сформировавшихся 
рынков услуг промышленного характера и продолжает развиваться высокими темпами и сегодня.

Внешнеторговая Энциклопедия дает следующее толкование инжиниринговых услуг: «услуги по подготовке процесса производства и реализации продукции (работ, услуг), подготовке строительства и эксплуатации промышленных, инфраструктурных, сельскохозяйственных и других объектов, предпроектные и проектные услуги (подготовка ТЭО, проектно-конструкторские разработки и другие подобные услуги)» [21, с. 136]. Иными словами, под инжиниринговыми услугами понимается совокупность инженерноконсультационных услуг по подготовке и обеспечению процесса производства, обслуживанию сооружений, эксплуатации хозяйственных объектов и реализации продукции. В широком смысле, под инжинирингом также понимается предоставление услуг по доведению научно-исследовательских и опытно-конструкторских разработок до стадии производства. Д. В. Рыбец и Е. И. Босин, говоря о роли науки в развитии инжиниринга, отмечают их тесную взаимосвязь: «По сути дела это единый процесс создания, апробирования и внедрения технических и технологических достижений, передовых решений и разработок. Наука генерирует новые идеи и решения, а инжиниринг доводит их до практического внедрения» [22].

В соответствии с международными стандартами PMI (project management institute) инжиниринг включает 4 процесса:

-E (engineering - проектирование);

-P (procurement - комплектация);

-C (constraction - строительство);

-PM (project management - управление проектом).

Д. В. Рыбец и Е. И. Босин выделяют в качестве функций инжиниринга следующие: -исследования - первоначальное изучение проблематики, поиск новых принципов и процессов;

-разработка - создание новых моделей в различных областях: технологических процессов, производственного оборудования и предприятий в целом;

-проектирование - проектирование процесса создания продукции или производственной системы, определение используемых материалов, характеристик и структуры продукции или системы;

-определение стоимостных и финансовых параметров проекта - разработка бюджетов и смет по проекту, подготовка и проведение конкурсов, создание новых финансовых инструментов и схем;

-организация производства - определение плана размещения производственных процессов, выбор и приобретение необходимого оборудования, сырья, материалов и компонентов, необходимых для производства и источников их поставки, интеграция всех производственных процессов, проведение инспекций, тестирования, пуско-наладочных работ, подготовка персонала;

-производство - контроль функционирования машин, процессов, систем, фабрик и заводов, организация материального и энергетического снабжения, транспорта, коммуникаций, определение процедур соблюдения технологических процессов и их усовершенствование, контроль деятельности персонала, управление качеством продукции [23].

Таким образом, инжиниринговые услуги представляют собой довольно широкое понятие и могут быть использованы практически на всех стадиях жизненного цикла промышленной продукции. «Функции инжиниринга объединяются в некоторую логико-временную последовательность, которая весьма сходна с моделью жизненного цикла проекта, - утверждают Д. В. Рыбец и Е. И. Босин. - Это сходство объясняется и тем, что 
инжиниринговая деятельность осуществляется, как правило, либо в рамках инвестиционно-строительных проектов, либо в виде отдельных инжиниринговых услуг, а проектный менеджмент, таким образом, становится базовой управленческой методологией инжиниринга» [23].

Сфера инжиниринговых услуг включает в себя помимо чисто инженерных услуг также услуги научно-технического и коммерческого характера, при этом последние растут все большими темпами. Упомянутые выше авторы Д. В. Рыбец и Е. И. Босин пишут по этому поводу: «Главный показатель конкурентоспособности прежних лет - цена в последние годы уступил место такому фактору, как финансовые условия реализации проектов, включая льготное кредитование, при этом возросла роль инжиниринговых компаний в решении вопросов финансирования проектов. Широкое развитие получил финансовый инжиниринг, который состоит в предоставлении заказчикам консультаций по проблемам финансирования в комплексе, в т. ч. по вопросам кредитов, гарантий, страхования, налогов, сборов. Это привело к расширению связей инжиниринговых фирм с банками, которые в ряде случаев становятся финансовыми партнерами» [23]. В связи с этим сегодня все чаще на крупных промышленных предприятиях формируется самостоятельное финансовое подразделение. Например, в рассматриваемом выше предприятии Siemens существует департамент финансовых услуг, действующий в двух направлениях: финансовое обеспечения производственной деятельности предприятия Siemens и предоставление финансовых услуг для клиентов Siemens и других компаний (финансирование покупки оборудования, проектное финансирование, структурированное финансирование в форме долговых и долевых инвестиций, лизинговые услуги) [2, p. 8]. В 2015 г. это подразделение оказалось одним из наиболее прибыльных: диапазон рентабельности составил $15-20 \%$ [2, p. 8].

Кроме того, в соответствии с мировыми тенденциями инжиниринговые предприятия стремятся оказать все более широкий перечень услуг, позволяющий реализовывать проекты «под ключ». «В России инжинирингом считается установка оборудования с пусконаладкой, - отмечают И. Д. Лифанов и А. И. Шинкевич. - В то время как в наиболее развитых странах практикуется продвинутый инжиниринг, охватывающий весь процесс проектирования и учитывающий жизненный цикл продукции» [20]. Е. А. Можаева к комплексной инжиниринговой услуге относит: научную разработку идеи; предынвестиционные исследования; технико-экономическое обоснование проекта; подготовку документации; экспертизу проекта; осуществление ряда строительных и контрольных функций на объектах проекта; финансовый и технический надзор за процессом строительства; предложение решений по более эффективному использованию; обучение работников фирмы; сервисное обслуживание оборудования проекта; вывод оборудования из эксплуатации; техническую реконструкцию [23].

Выделяют две категории инжиниринговых фирм: специализированные инжиниринговые фирмы и промышленные фирмы, сочетающие оказание инженерных услуг с производственной деятельностью. Традиционной моделью развития мирового рынка инжиниринговых услуг является сначала формирование инжиниринговых структурных подразделений внутри крупнейших промышленных компаний. Для производителей оборудования оказание инжиниринговых услуг является средством увеличения продаж основной продукции. Компании-проектировщики, стремясь сохранить секреты производства, выполняют технологическое проектирование с целью расширения или создания нового производства на основе собственных патентов и ноу-хау, а подрядчики используются для выполнения остальных инженерно-консультационных работ, осуществляя контроль их выполнения [24]. Так, как уже отмечалось выше, предприятие Siemens наряду с про- 
изводственными департаментами электроэнергетики и газа и ветроэнергетики и возобновляемых источников энергии имеют самостоятельный департамент услуг в сфере производства электроэнергии [2].

К специализированным фирмам относят инженерно-консультационные и инженерно-строительные фирмы. Сферой деятельности инженерно-строительной фирмы является как гражданское строительство (порты, аэродромы, транспортные магистрали, шахты, городское строительство), так и промышленные объекты, использующие специфические технологические процессы. Инжиниринговые услуги широко применяются при разработке и реализации промышленных инвестиционных проектов. Как правило, такие предприятия оказывают полный комплекс инженерно-технических услуг, включая проектирование объекта, поставку оборудования, монтаж, наладку и пуск оборудования в эксплуатацию. Зачастую специализированные инжиниринговые фирмы являются аффилированными лицами промышленных предприятий (филиалами или дочерними компаниями крупных генеральных подрядчиков, занимающихся инжиниринговой деятельностью как вспомогательной для основного производства) [24].

Согласно данным Международной федерации инженеров-консультантов FIDIC основную долю мирового рынка (до 75 \%) составляет строительный инжиниринг, на втором месте технологический инжиниринг (10\%), и 5 \% приходится на консультационный инжиниринг [20]. В Беларуси, как и в России, большую часть спроса на инжиниринговые услуги обеспечивают масштабные капиталоемкие проекты, финансируемые в той или иной степени государством и которые могут выполнять только крупные инжиниринговые компании. Наряду с крупными фирмами действуют средние и мелкие инжиниринговые фирмы, специализирующиеся в узком диапазоне услуг и обычно выступающих в роли субподрядчиков. Однако, как правило, крупнейшие предприятия-заказчики предпочитают в качестве субподрядчиков узкий круг аффилированных инжиниринговых структур, что отрицательно сказывается на развитии малого и среднего бизнеса в этой сфере деятельности. Следует отметить, что в зарубежной практике наблюдается тенденция к увеличению субподрядных контрактов на предпроектные и проектные услуги [22].

Сегодня поставка машин, оборудования, средств коммуникаций и инновационных технологий сопровождается инжиниринговыми услугами, в связи с чем, значение рынка инжиниринговых услуг трудно переоценить. Сохранение высокого уровня спроса со стороны промышленности на инженерно-консультационные услуги обусловлено, вопервых, необходимостью проведения модернизации современного промышленного производства на постоянной основе, а, следовательно, и регулярного использования инжиниринговых услуг; во-вторых, технико-технологическим усложнением всех стадий жизненного цикла промышленной продукции, что требует их специализированного комплексного обслуживания инжиниринговыми фирмами; в-третьих, интенсификацией инвестиционной деятельности в сфере промышленности, неотъемлемой составляющей которой являются инжиниринговые услуги.

Особое значение в современном промышленном производстве играют информационно-коммуникационные услуги, создающие новую цифровую инфраструктуру. Доля информационно-коммуникационных услуг, потребляемых промышленностью, сравнительно невелика (в Германии - 11,5 \% [8], в Беларуси - 5,25 \% (сфера производства в целом)). Более слабая взаимосвязь объясняется специалистами в том числе «сквозным характером информационно-коммуникационной отрасли» [8], с чем невозможно не согласиться. Информационно-коммуникационные услуги промышленного характера, в частности, промышленный интернет вещей, в дальнейшем будут находить все более широкое применение, создавая новую архитектуру производства, управления и реализа- 
ции продукции. По данным McKinsey объем рынка интернета вещей в 2015 г. оценивается в 900 млрд. долл., к 2020 г. прогнозируется рост до 3,7 трлн. долл. [25, с. 168]. Предпосылками столь интенсивного развития рынка промышленного интернета вещей являются, с одной стороны, новые организационные возможности бизнеса («умные» заводы, «умные» решения), с другой стороны - возможности выстраивания новых бизнес-моделей, меняющих традиционное преставление о взаимодействии с клиентами и формировании цены производимой продукции. Как отмечалось нами ранее, предполагается, что внедрение промышленного интернета вещей «повысит эффективность труда на предприятиях, позволит экономить на плановом ремонте оборудования и общих эксплуатационных затратах, минимизирует аварии на производстве и в целом увеличит предсказуемость промышленных систем. На макроуровне это приведет к росту энергоэффективности и конкурентоспособности экономики, стиранию границ между отраслями, снижению техногенного влияния на окружающую среду» [26, с. 70]. Также информационно-коммуникационные технологии влияют на трансформацию трудовых отношений. Т. В. Сергиевич характеризует особенности изменения современных трудовых отношений следующим образом: «Стремительные изменения внешней среды социально-экономических систем, трансформации их внутренних структур, нарастающее давление практики управления, обусловленное несоответствием ей устоявшихся подходов к управлению трудом, требуют поиска новых решений старых задач, как повышение производительности труда, формирование мотивационной системы субъектов управления трудом, эффективное использование трудового потенциала, оптимизация структуры занятости» [27, с. 262]. Характеризуя товары интенсивного обновления, этот автор отмечает, что «чем выше уровень творческой и интеллектуальной составляющих в труде, тем сложнее должна быть система трудовой мотивации, сочетающая в себе как материальные, так и нематериальные факторы» [28, с. 276], что справедливо и для услуг промышленного характера.

Международный опыт показывает, что государственный сектор является основным драйвером роста интернета вещей. Государство стимулирует распространение технологий ІоТ через госпрограммы цифровизации и автоматизации управления городской инфраструктуры. Роль государства как основного потребителя технологий интернета вещей объективно обусловлено дороговизной и рискованностью, характерных для всех новых технологий. Кроме того, С. Ю. Солодовников указывает: «Для трансформационной экономики (к которой, в случае форсирования перехода к новому информационному технологическому укладу будет относиться в ближайшие годы социально-ориентированная белорусская экономическая система) в целом характерна неустойчивость, альтернативный характер развития и резко возрастающая роль субъективного фактора. Соответственно возрастает, по сравнению с непереходными системами, роль государства в управлении социальными, экономическими и технико-технологическими процессами в обществе» [29, с. 446].

В Беларуси также государство выступает основным заказчиком услуг промышленного интернета вещей, одной из первых сфер внедрения интернета вещей в экономику Беларуси стала жилищно-коммунальная сфера. Сегодня для распространения интернета вещей в нашей стране созданы коммуникационные сети и центры обработки данных, имеется достаточное количество устройств интернета вещей (датчиков, сенсоров). Вместе с тем специалистами отмечается нехватка программных продуктов, направленных на решение задач бизнеса - готовых сервисов, что выступает препятствием для развития промышленного интернета вещей. 


\section{ВЫВОДЫ}

Направления развития услуг промышленного характера в Республике Беларусь как в стране с малой открытой экономикой в целом совпадают с основными общемировыми тенденциями. В частности, терциализация обрабатывающей промышленности в Беларуси продолжает углубляться, при этом в большей степени в высокотехнологичных (наукоемких) и экспортоориентированных видах деятельности. Дальнейший рост доли услуг промышленного характера обусловлен как повышением научно-технологического уровня производства, так и тенденциями кастомизации белорусской промышленности. В связи с этим наиболее перспективными представляются такие услуги промышленного характера, как: услуги по разработке и внедрению продукции в производство, позволяющие предприятиям добиться уникальных технико-технологических преимуществ и сформировать базу для дальнейшего роста; услуги, сопровождающие промышленную продукцию, направленные на расширение возможности потребления, содержания и эксплуатации продукции; информационно-коммуникационные услуги, создающие новые организационные модели производства, управления и реализации продукции.

\section{СПИСОК ИСПОЛЬЗОВАННЫХ ИСТОЧНИКОВ}

1.Eickelpasch, A. Industrie und industrienahe Dienstleistungen in der Region FrankfurtRheinMain / A. Eickelpasch, R. Behrend und D. Krüger-Röth. - Berlin: DIW Berlin, 2017. $137 \mathrm{~s}$.

2.Siemens. Annual Report 2016 [Electronic Resource] // 2016 by Siemens AG, Berlin and Munich. - Access mode: siemens.com. - Access Date: 01.06.2018.

3.Продуктовая структура затрат отечественных товаров и услуг (в процентах) // Система таблиц «Затраты-Выпуск» Республики Беларусь за 2015 год. - Мн.: Национальный статистический комитет Республики Беларусь, 2017. - 104 с. - С. 68-70.

4.Sechs fragen an Alexander Eickelpasch: «Immer weniger Industrie-beschäftigte arbeiten in der Fertigung» // DIW Wochenbericht. - 2014. - Nr. 33. - S. 771.

5.Солодовников, С. Ю.Цивилизация, культура, экономическая система общества и институциональные матрицы: феноменологическая природа и взаимообусловленность / С. Ю. Солодовников // Веснік Гродзенскага дзяржаўнага ўніверсітэта імя Янкі Купалы. Серыя 5: Эканоміка. Сацыялогія. Біялогія. - 2011. - № 2 (120). - С. 10-25.

6.Мелешко, Ю. В. Значение услуг промышленного характера в повышении конкурентоспособности промышленных предприятий (в контексте четвертой промышленной революции) / Ю. В. Мелешко // Экономическая наука сегодня : сб. науч. ст. / БНТУ. Минск, 2017. - №6. - С. 64-78.

7.Eickelpasch, A. Forschung und Entwicklung in der Industrie: Unternehmen stehen besser da denn je / A. Eickelpasch // DIW Wochenbericht. - 2013. - Nr. 31. - S. 695-708.

8.Edler, D. Die Industrie - ein wichtiger Treiber der Nachfrage nach Dienstleistungen / D. Edler, A. Eickelpasch // DIW Wochenbericht. - 2013. - Nr. 34. - S. 16-23. - S. 21.

9.Солодовников, С. Ю. Тенденции и перспективы развития занятости и создания социально-научного сообщества в условиях модернизации транзитивной экономики: на примере Республики Беларусь / С. Ю. Солодовников // Вестн. Полоц. гос. ун-та. Сер. D. Экон. и юрид. науки. - 2015. - № 6. - C. 2-9.

10.Солодовников, С. Ю. Социально-экономические условия перехода Республики Беларусь к постиндустриальному обществу / С. Ю. Солодовников // Известия Самарского научного центра Российской академии наук. - 2007. - Т. 9. - № 2. - С. 443-448. 
11.Солодовников, С. Ю. Новая структурная политика и изменение институциональной динамики наноиндустрии / С. Ю. Солодовников // Ресурсы Европейского Севера, Технологии и экономика освоения. - 2018. - № 01 (11). - С. 5-10.

12.Васюченок, Л. П. Особенности трансфера технологий в белорусской экономике / Л. П. Васюченок // Экономическая наука сегодня : сб. науч. ст. / БНТУ. - Минск, 2016. - № 4. - С. 84-94.

13.Андриянова, Ю. А. Проблемы предоставления качественных услуг в промышленной сфере / Ю. А. Андриянова // Вестник Чувашского государственного педагогического университета им. И. Я. Яковлева. - 2013. - №4-2. - С. 8-12. - С. 9.

14.Mödinger, P., Redling, B. (2004): Produktbegleitende Dienstleistungen im Industrieund Dienstleistungssektor im Jahr 2002. Wirtschaft und Statistik (12), 1408 - 1413. - S. 1408

15.Industrienahe Dienstleistungen [Elektronische Ressource] // Wirtschaftslexikon. Zugriffsmodus: http://www.wirtschaftslexikon.co /d/industrienahe -dienstleistungen/industrienahe-dienstleistungen.htm. - Zugriffsdatum: 25.05.2018.

16.Strähle, O. Füllemann, M. et al. (2012): Service now! Time to wake up the sleeping giant, München.

17.Stille, F. (2003): Produktbegleitende Dienstleistungen gewinnen weiter an Bedeutung. Wochenbericht des DIW 70 (21), $336-342$.

18.Bienzeisler, B., Kunkis, M. (2008): Dienen und mehr verdienen? Hybride Wertschöpfung im Maschinen-und Anlagenbau. Stuttgart.

19.Ивашкова, Н. И. Маркетинговый подход к развитию промышленных сервисных услуг / Н. И. Ивашкова, Е. И. Карякин // Инициативы XXI века. - 2013. - № 4. C. $73-76$.

20.Лифанов, И. Д. Основные тенденции формирования и развития рынка инжиниринговых услуг в России / И. Д. Лифанов, А. И. Шинкевич // Вестник Казанского технологического университета. - 2014. - Т. 17. - № 5. - С. 333-338.

21.Внешнеторговая Энциклопедия / Отв. ред. С.И. Долгов. - М.: Экономика, 2011.

22.Рыбец, Д. В. Этапы развития инжиниринговых (инженерно-консультационных) услуг на мировом рынке / Д. В. Рыбец, Е. И. Босин // Российский внешнеэкономический вестник. $-2016 .-$ С. 101-111.

23.Можаева, Е. А. Основные направления инновационного развития в сфере инжиниринговых услуг / Е. А. Можаева // Вестник Хабаровского государственного университета экономики и права. 2015. № 6 (80). - С. 19-23.

24.3орин, М. В. Развитие инжиниринга в строительстве на основе логистической поддержки / М. В. Зорин // Российское предпринимательство. - 2012. - №22(220). C. $105-110$.

25.Грингард, С. Интернет вещей. Будущее уже здесь / С. Грингард. - М.: Альпина Паблишер, 2016. - 185 с.

26.Мелешко, Ю. В. Становление мирового рынка промышленного интернета вещей / Ю. В. Мелешко // Устойчивое развитие экономики: состояние, проблемы, перспективы: сборник трудов XII междунар. науч.-практ. конф., УО «ПолессГУ», г. Пинск, 27 апреля 2018 г. / Министерство образования Республики Беларусь [и др.]; редкол.: К. К. Шебеко [и др.]. - Пинск : ПолесГУ, 2018. - 268 с. - С. 69-71.

27.Сергиевич, Т. В. Трудовой потенциал и управление трудом в текстильной и швейной промышленности как объекты экономического исследования / Т. В. Сергиевич // Экономическая наука сегодня : сб. науч. ст. / БНТУ. - Минск, 2017. - № 5. - С. 260 275.

28.Сергиевич, Т. В. Мода как фактор интенсивного обновления товаров / Т. В. Сергиевич // Российская экономика: взгляд в будущее : материалы III Международной 
научно-практической конференции (заочной): в 2 частях. Часть 1, г. Тамбов, 17 февраля 2017 г. / М-во обр. и науки РФ; ФГБОУ ВО «Тамб. гос. ун-т им. Г.Р. Державина»; [отв. ред. Я. Ю. Радюкова]. Тамбов: Издательский дом ТГУ им. Г.Р. Державина, 2017. C. 275-282.

29.Солодовников, С. Ю. Социально-экономические условия перехода Республики Беларусь к постиндустриальному обществу / С. Ю. Солодовников // Известия Самарского научного центра Российской академии наук. - 2007. - Т. 9. - № 2. - С. 443-448.

\section{REFERENCES}

1.Eickelpasch, A. Industrie und industrienahe Dienstleistungen in der Region Frankfurt RheinMain / A. Eickelpasch, R. Behrend und D. Krüger-Röth. - Berlin: DIW Berlin, 2017. $137 \mathrm{~s}$.

2.Siemens. Annual Report 2016 [Electronic Resource] // 2016 by Siemens AG, Berlin and Munich. - Access mode: siemens.com. - Access Date: 01.06.2018.

3.Produktovaja struktura zatrat otechestvennyh tovarov i uslug (v procentah) // Sistema tablic «Zatraty-Vypusk» Respubliki Belarus' za 2015 god. - Mn.: Nacio-nal'nyj statisticheskij komitet Respubliki Belarus', 2017. - 104 s. - S. 68-70.

4.Sechs fragen an Alexander Eickelpasch: «Immer weniger Industrie-beschäftigte arbeiten in der Fertigung»// DIW Wochenbericht. - 2014. - Nr. 33. - S. 771.

5.Solodovnikov, S. Ju. Civilizacija, kul'tura, jekonomicheskaja sistema ob-shhestva I institucional'nye matricy: fenomenologicheskaja priroda i vzaimoobu-slovlennost' / S. Ju. Solodovnikov // Vesnik Grodzenskaga dzjarzhay̆naga y̆niversitjeta imja Janki Kupaly. Seryja 5: Jekanomika. Sacyjalogija. Bijalogija. - 2011. - № 2 (120). - S. 10-25.

6.Meleshko, Ju. V. Znachenie uslug promyshlennogo haraktera $\mathrm{v}$ povyshenii konkurentosposobnosti promyshlennyh predprijatij (v kontekste chetvertoj pro-myshlennoj revoljucii) / Ju. V. Meleshko// Jekonomicheskaja nauka segodnja: sbornik nauchnyh statej / BNTU; redkol.: S. Ju. Solodovnikov (pred. redkol.) [i dr.]. - Minsk: BNTU, 2017. - № 6. S. 64-78.

7.Eickelpasch, A. Forschung und Entwicklung in der Industrie: Unternehmen stehen besser da denn je / A. Eickelpasch // DIW Wochenbericht. - 2013. - Nr. 31. - S. 695-708.

8.Edler, D. Die Industrie - ein wichtiger Treiber der Nachfrage nach Dienstleistungen / D. Edler, A. Eickelpasch // DIW Wochenbericht. - 2013. - Nr. 34. - S. 16-23. - S. 21.

9. Solodovnikov, S. Ju. Tendencii i perspektivy razvitija zanjatosti i so-zdanija social'nonauchnogo soobshhestva $\mathrm{v}$ uslovijah modernizacii tranzitivnoj jeko-nomiki: na primere Respubliki Belarus' / S. Ju. Solodovnikov // Vestn. Poloc. gos. un-ta. Ser. D. Jekon. i jurid. nauki. - 2015. - № 6. - S. 2-9.

10.Solodovnikov, S. Ju. Social'no-jekonomicheskie uslovija perehoda Respub-liki Belarus' k postindustrial'nomu obshhestvu / S. Ju. Solodovnikov // Izvestija Samarskogo nauchnogo centra Rossijskoj akademii nauk. - 2007. - T. 9. - № 2. - S. 443-448.

11.Solodovnikov, S. Ju. Novaja strukturnaja politika i izmenenie instituci-onal'noj dinamiki nanoindustrii / S. Ju. Solodovnikov // Resursy Evropejskogo Severa, Tehnologii I jekonomika osvoenija. - 2018. - № 01 (11). - S. 5-10.

12.Vasjuchenok, L. P. Osobennosti transfera tehnologij v belorusskoj jekono-mike / L. P. Vasjuchenok // Jekonomicheskaja nauka segodnja: sbornik nauchnyh statej / BNTU; redkol.: S. Ju. Solodovnikov (pred. redkol.) [i dr.]. - 2016. - № 4. - S. 84-94.

13.Andrijanova, Ju. A. Problemy predostavlenija kachestvennyh uslug v promyshlennoj sfere / Ju. A. Andrijanova // Vestnik Chuvashskogo gosudarstvennogo pedagogicheskogo universiteta im. I. Ja. Jakovleva. - 2013. - № 4-2. - S. 8-12. 
14.Mödinger, P., Redling, B. (2004): Produktbegleitende Dienstleistungen im Industrieund Dienstleistungssektor im Jahr 2002. Wirtschaft und Statistik (12), 1408 - 1413. - S. 1408

15.Industrienahe Dienstleistungen [Elektronische Ressource] // Wirtschaftslexikon. Zugriffsmodus: http://www.wirtschaftslexikon.co /d/industrienahe -dienstleistungen/industrienahe-dienstleistungen.htm. - Zugriffsdatum: 25.05.2018.

16.Strähle, O. Füllemann, M. et al. (2012): Service now! Time to wake up the sleeping giant, München.

17.Stille, F. (2003): Produktbegleitende Dienstleistungen gewinnen weiter an Bedeutung. Wochenbericht des DIW 70 (21), $336-342$.

18.Bienzeisler, B., Kunkis, M. (2008): Dienen und mehr verdienen? Hybride Wertschöpfung im Maschinen-und Anlagenbau. Stuttgart.

19.Ivashkova, N. I. Marketingovyj podhod k razvitiju promyshlennyh ser-visnyh uslug / N. I. Ivashkova, E. I. Karjakin // Iniciativy XXI veka. - 2013. - №4. - S. 73-76.

20.Lifanov, I. D. Osnovnye tendencii formirovanija i razvitija rynka in-zhiniringovyh uslug v Rossii / I. D. Lifanov, A. I. Shinkevich // Vestnik Kazanskogo tehnologicheskogo universiteta. - 2014. - T. 17. - № 5. - S. 333-338.

21.Vneshnetorgovaja Jenciklopedija / Otv. red. S.I. Dolgov. - M.: Jekonomika, 2011.

22.Rybec, D. V. Jetapy razvitija inzhiniringovyh (inzhenerno-konsul'tacionnyh) uslug na mirovom rynke / D. V. Rybec, E. I. Bosin // Rossijskij vneshnejekonomicheskij vestnik. 2016. - S. 101-111.

23.Mozhaeva, E. A. Osnovnye napravlenija innovacionnogo razvitija v sfere inzhiniringovyh uslug / E. A. Mozhaeva // Vestnik Habarovskogo gosudarstvennogo universiteta jekonomiki i prava. 2015. № 6 (80). - S. 19-23.

24.Zorin, M. V. Razvitie inzhiniringa $\mathrm{v}$ stroitel'stve na osnove logistiche-skoj podderzhki / M. V. Zorin // Rossijskoe predprinimatel'stvo. - 2012. - №22(220). - S. 105-110.

25.Gringard, S. Internet veshhej. Budushhee uzhe zdes' / S. Gringard. - M.: Al'-pina Pablisher, 2016. - $185 \mathrm{~s}$.

26.Meleshko, Ju. V. Stanovlenie mirovogo rynka promyshlennogo interneta veshhej / Ju. V. Meleshko// Ustojchivoe razvitie jekonomiki: sostojanie, problemy, per-spektivy: sbornik trudov XII mezhdunarodnoj nauchno-prakticheskoj konferencii, UO «Polesskij gosudarstvennyj universitet», g. Pinsk, 27 aprelja 2018 g. / Minister-stvo obrazovanija Respubliki Belarus' [i dr.]; redkol.: K.K. Shebeko [i dr.]. - Pinsk : PolesGU, 2018. - 268 s. - S. 69-71.

27.Sergievich, T. V. Trudovoj potencial i upravlenie trudom $v$ tekstil'noj i shvejnoj promyshlennosti kak ob\#ekty jekonomicheskogo issledovanija / T. V. Sergievich // Jekonomicheskaja nauka segodnja: sbornik nauchnyh statej / BNTU; redkol.: S. Ju. Solodovnikov (pred. redkol.) [i dr.]. - 2017. - № 5. - S. 260-275.

28.Sergievich, T. V. Moda kak faktor intensivnogo obnovlenija tovarov / T. V. Sergievich // V sbornike: rossijskaja jekonomika: vzgljad v budushhee: materialy III mezh-dunarodnoj nauchno-prakticheskoj konferencii (zaochnoj): v 2 chastjah. - 2017. - S. 275-282.

29.Solodovnikov, S. Ju. Social'no-jekonomicheskie uslovija perehoda Respub-liki Belarus' k postindustrial'nomu obshhestvu / S. Ju. Solodovnikov // Izvestija Samarskogo nauchnogo centra Rossijskoj akademii nauk. - 2007. - T. 9. - № 2. - S. 443-448.

Статья поступила в редакцию 29 сентября 2018 года. 